\title{
ĐăC ĐIỂM HÌNH ẢNH SIÊU ÂM TUYẾN VÚ SAU SINH THIẾT có Hỗ TRợ HÚT CHÂN KHÔNG DƯớI HƯớNG DẪN SIÊU ÂM
}

\author{
Nguyễn Thị Hoa ${ }^{a}$, Nguyễn Duy Trinh ${ }^{b}$, Nguyễn Thị Ngọc Minh ${ }^{c}$, \\ Lưu Hồng Nhungc, Lại Thu Hương ${ }^{c}$, Nguyễn Thị Thanh Thủyc, \\ Nguyễn Thị Thu Huyền ${ }^{a}$, Phạm Việt Hàa, Vũ Đăng Lưu ${ }^{\mathrm{c}}$
}

\section{TÓM TẮT}

Muc tiêu: Đánh giá hình ảnh siêu âm tuyến vú theo dõ̃i sau hút bỏ u vú bằng phương pháp sinh thiết có hỗ trợ hút chân không (VABB) dưới hướng dẫn siêu âm. Đối tượng và phương pháp: Nghiên cứu tiến cứu và hồi cứu gồm 143 bệnh nhân với 190 tổn thương được thực hiện tại Trung tâm điện quang Bệnh viện Bạch Mai từ 8/2018 đến 8/2021. Kết quả: Theo dối sau hút 1 tháng thấy biến chứng chủ yểu là máu tụ $(87.4 \%)$, theo dõi sau $1-3$ năm cho thấy hâu hết các tổn thương không để lai dấu vết (từ $75 \%$ theo dõi sau $1-2$ năm lên $84.2 \%$ sau hút 2 năm trở lên) hoăc chỉ có seo nhỏ hoăc biến dang cấu trúc nhỏ, chỉ có một trường hợp còn sót u phát hiện sau hút 1 năm do yếu tố khách quan. Thể tích sẹo trung bình sau hút $1-2$ năm là $0.01 \pm 0.03 \mathrm{~cm}^{3}$, sau 2 năm là $0.01 \pm$ $0.02 \mathrm{~cm}^{3}$. Có mối tương quan tuyến tính thuân giữa máu tụ và sẹo sau hút với thể tích u và số mảnh cắt, giữa sẹo và thể tích máu tư sau hút. Kết luận: VABB là một phương pháp an toàn, hiệu quả, có tính thẩm mỹ cao, chẩn đoán chính xác tổn thương vú, là lựa chọn đề điều trị các u vú lành tính.

Tư khóa: u vú lành tính, sinh thiết vú có hỗ trợ hút chân không dưới hướng dần siêu âm

Các chữ viết tắt: $\mathrm{VABB}$ : sinh thiết vú có hỗ trợ hút chân không, NC: nghiên cứu, BN: bệnh nhân

\section{SUMMARY \\ CHARACTERISTICS OF BREAST ULTRASOUND IMAGES AFTER ULTRASOUND-GUIDED VACUUM ASSISTED BREAST BIOPSY}

Aim: To evaluate breast ultrasound images followed-up after complete excision of benign breast tumors by ultrasound-guided vacuum assisted breast biopsy (VABB). Subjects and methods: This is a prospective and retrospective study of 143 patients with 190 lesions at the Radiology Center - Bach Mai Hospital from August 2018 to August 2021. The patients had undergone VABB device excision of benign breast tumors and been followed up by ultrasonography for 1- 3 years. Results: Within 1 month of follow-up, the main complication was hematoma $(87.4 \%)$, after $1-3$ years of follow-up, most of the lesions did not leave any traces (from $75 \%$ after

aTrường Đại học Y Dược - Đại học Thái Nguyên

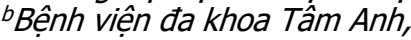

'Bềnh viền Bach mai

Chịu trách nhiệm chính: Nguyễn Thị Hoa

Email: drhoa.radiology@gmail.com

Ngày nhận bài: 6.7.2021

Ngày phản biên khoa hoc: 30.8.2021

Ngày duyệt bài: 8.9.2021
$1-2$ years of follow-up to $84.2 \%$ after 2 years) or only had minimal scars or minimal parenchyma distortion. There was only one case of residual tumor detected 1 year after excision due to objective factors. The average scar volume after $1-2$ years of follow-up is $0.01 \pm 0.03 \mathrm{~cm}^{3}$ and $0.01 \pm 0.02 \mathrm{~cm}^{3}$ after 2 years. There is a positive linear relationship between hematoma and scar with tumor volume and number of spicimens and between scar and hematoma after excision. Conclusion: VABB is a safe, effective, highly cosmetic method, accurately diagnose of breast lesions, and it is the choice for the treatment of benign breast tumors.

Keywords: benign breast tumor, ultrasoundguided vacuum assisted breast biopsy, VABB

\section{I. ĐĂT VẤN ĐỀ}

Bệnh vú là một trong các bệnh lý phổ biến nhất ở nữ giới, trong đó các bệnh vú lành tính chiếm đa số. Mặc dù các u lành tuyến vú không gây đe dọa đến tính mạng nhưng đáng chú ý do tỉ lệ mắc cao, tăng kích thước, gây ảnh hưởng đến thẩm mỹ hoặc chất lượng cuộc sống của người bệnh. Do đó việc loại bỏ các tổn thương lành tính là cần thiết và phần lớn bệnh nhân đều mong muốn loại bỏ hoàn toàn u bằng kỹ thuật xâm lấn tối thiểu.

Sinh thiết vú có hỗ trợ hút chân không (VABB - Vaccum-assisted Breast Biopsy) dưới hướng dẫn siêu âm được giới thiệu từ cuối thập niên 90 của thế kỷ 19 và được chứng minh là một phương pháp mới có giá trị trong điều trị các tổn thương tuyến vú ${ }^{1}$. Những lợi ích và hiệu quả của phương pháp đã được nhiều tác giả trong và ngoài nước NC, nhưng vẫn còn nhiều tranh cãi trong việc theo dõi các tổn thương sau hút. Do đó, nghiển cứu đặc điểm hình ảnh tuyến vú theo dõi sau hút ở các thời điểm khác nhau nhằm cung cấp thêm thông tin cho các bác sỹ lâm sàng và chẩn đoán hình ảnh trong việc đánh giá tổn thương vú sau điều trị bằng phương pháp này.

\section{II. ĐỐI TƯỢNG VÀ PHƯƠNG PHÁP NGHIÊN CỨU}

1. Đối tượng nghiên cứu. Các $B N(B N)$ được chỉ định VABB dưới siêu âm với mục đích điều trị (190 tổn thương trên $143 \mathrm{BN}$ ) được thực hiện tại Trung tâm điện quang - Bệnh viện Bạch Mai từ $8 / 2018$ đến $8 / 2021$.

1.1. Tiêu chuẩn lựa chọn $B N$ : các $B N$ 
trong NC phải có đủ các tiêu chuẩn sau:

- BN có chỉ định loại bỏ u vú lành tính bằng phương pháp VABB dưới siêu âm

- BN có đầy đủ thông tin và hồ sơ bệnh án.

- BN đồng ý tham gia vào NC.

Chỉ định điều trị loại bỏ u vú lành tính dưới siêu âm bằng phương pháp VABB:

- Các tổn thương trong lòng ống tuyến, trong lòng nang (ví dụ: u nhú).

- Các tổn thương lành tính, có triệu chứng (ví dụ: $u \times \sigma)^{\prime}$.

- Bệnh nhân quá lo lắng về u vú hoặc không có điều kiên theo dõi định kỳ.

1.2. Tiêu chuẩn loại trừ: loại trừ các $B N$ không đủ tất cả các tiêu chuẩn trên.

2. Phương pháp NC: mô tả cắt ngang tiến cứu và hồi cứu

Các BN được theo dõi bằng siêu âm ngay sau hút, sau hút 1 ngày, 1 tuần, 1 tháng và $1-3$ năm, đánh giá hình ảnh tuyến vú sau hút và mối tương xứng với giải phẫu bệnh.

3. Phương tiện NC: máy siêu âm ALOKA ARIETTA với đầu dò Linear $9 \mathrm{MHz}$ và máy hút chân không Bard hoặc Bexcore, sử dụng kim sinh thiết vú Bard (cỡ kim 7G hoặc 10G) hoặc Bexcore (8G hoăc 10G).

4. Phân tích số liệu: bằng phần mềm thống kê y học SPSS 20.0

\section{KẾT QUẢ NGHIÊN CỨU}

1. Một số đặc điểm chung của đối tượng NC. NC gồm 141 BN nữ với 190 tổn thương.Tuổi trung bình là $32 \pm 9$ (17- 65 tuổi), độ tuổi hay gặp nhất từ 20 - 40 tuổi $(74.2 \%), 58.4 \%$ dưới 35 tuổi.

Đường kính lớn nhất trung bình của các u là $18.5 \pm 8.6 \mathrm{~mm}$ (từ $3-50 \mathrm{~mm}$ ), trong đó $173 / 190$ (91.1\%) u có đường kính dưới $3 \mathrm{~cm}, 17 / 190$ $(8.9 \%)$ có đường kính từ $3 \mathrm{~cm}$ trở lên. Thể tích u trung bình là $2.31 \pm 3.88 \mathrm{~cm}^{3}\left(0.03-30.38 \mathrm{~cm}^{3}\right)$. Trong đó tỉ lệ gặp nhiều nhất ở nhóm có thể tích dưới $2.5 \mathrm{~cm}^{3}$ (Biểu đồ 1).

Tỉ lệ u vú phải nhiều hơn vú trái, chiếm $55.8 \%$, hay gặp nhất ở vị trí góc $1 / 4$ trên ngoài $(43.2 \%)$, có $2(1.1 \%)$ trường hợp u dưới núm vú. Khoảng cách từ u đến núm vú trung bình là $21.2 \pm 12.2 \mathrm{~mm}(0-60 \mathrm{~mm})$, khoảng cách đến da trung bình là $5.1 \pm 2.7 \mathrm{~mm}(1.9-15 \mathrm{~mm})$, khoảng cách đến cơ ngực trung bình là $2.1 \pm 2.5$ $\mathrm{mm}(0-11 \mathrm{~mm})$. BN được hút u vú bằng các kim cõ 7G (3/190 tổn thương, 1.6\%), 8G (22/190 tổn thương, 11.6\%), 10G (165/190 tổn thương, 86.8\%). Số lượng u được hút trung bình 1 lần là $1.7 \pm 0.9$ (nhiều nhất là 6).

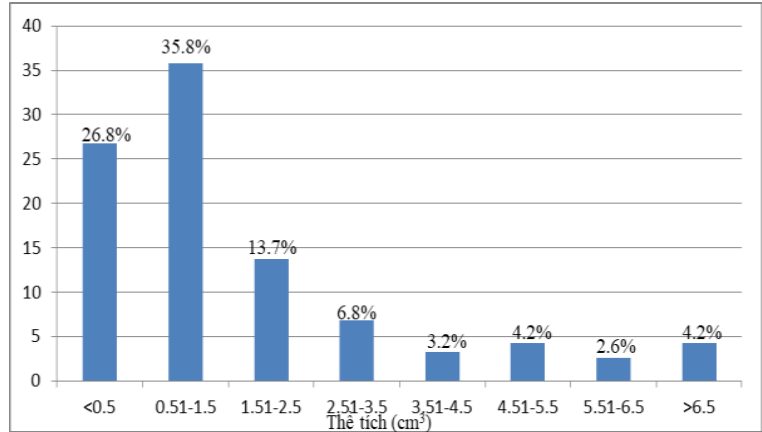

Biểu đồ 1: Phân bố tỉ lệ phân trăm các ca bệnh theo thể tích.

2. Đặc điểm hình ảnh siêu âm tuyến vú sau hút u vú 1 tháng. Hình ảnh biến chứng sớm hay gặp nhất sau hút là máu tụ tại vị trí hút u, chiếm $87.4 \%$, tụ khí tại vị trí hút chiếm $20.4 \%$.

Sau hút 1 ngày có 158 tổn thương được theo dõi, thể tích máu tụ trung bình là $1.51 \pm 4.78$ $\mathrm{cm}^{3}\left(0-40.6 \mathrm{~cm}^{3}\right)$. Sau hút 1 tuần có 87 tổn thương được theo dõi, thể tích máu tụ trung bình là $1.45 \pm 4.38 \mathrm{~cm}^{3}\left(0-38.1 \mathrm{~cm}^{3}\right)$. Sau hút 1 tháng có 137 tổn thương được theo dõi, 52 tổn thương không để lại dấu vết (38\%), 36 tổn thương còn để lại ổ dịch $(26.3 \%)$, 55 tổn thương đã tao seo $(35.7 \%)$. Thể tích ổ dịch trung bình là $0.92 \pm 2.75 \mathrm{~cm}^{3}\left(0.04-17.4 \mathrm{~cm}^{3}\right)$. Thể tích sẹo trung bình là $0.03 \pm 0.05 \mathrm{~cm}^{3}\left(0.01-0.3 \mathrm{~cm}^{3}\right)$.

NC của chúng tôi thây có mối tương quan tuyến tính thuận giữa máu tụ sau hút với thể tích khối $(r=0.17, p=0.03)$ và số mảnh cắt $(r=$ $0.13, p=0.02$ ). Biến chứng máu tụ ở nhóm dùng kim $8 \mathrm{G}$ cao nhất $95.7 \%$, nhóm $10 \mathrm{G}$ là $85.6 \%$ và nhóm $7 \mathrm{G}$ là $56 \%$, không có ý nghĩa thống kê.

Các khối có thể tích $<1.5 \mathrm{~cm}^{3}$ có thể tích máu tụ trung bình $0.68 \pm 1.89 \mathrm{~cm}^{3}$, các khối có thể tích $\geq 1.5 \mathrm{~cm}^{3}$ có thể tích máu tụ trung bình 3.07 $\pm 7.54 \mathrm{~cm}^{3}(p=0.002)$.

3. Đặc điểm hình ảnh siêu âm tuyến vú sau hút u vú 1 - 3 năm

Sau hút $1-2$ năm có 84 tổn thương được theo dõi, 63 (75\%) tổn thương không để lai dấu vết, $18(21.4 \%)$ tổn thương để lại sẹo với thể tích trung bình là $0.01 \pm 0.03 \mathrm{~cm}^{3}(0.01-$ $0.2 \mathrm{~cm}^{3}$ ) trong đó $5 / 18(27.8 \%)$ sẹo có co kéo da, $1(1.2 \%)$ tổn thương chưa hết u, 1 (1.2\%) tổn thương sau hút có biến đổi cấu trúc nhu mô tuyến $(1.2 \%), 1(1.2 \%)$ tổn thương còn ổ máu tụ nhỏ (Bảng 1).

Bảng 1: Kêt quả theo dôi sau điều trị hút bó u vú lành tính 1 - 3 năm

\begin{tabular}{|l|c|c|}
\hline Hình ảnh theo & 1 - 2 năm & $\geq 2$ năm \\
\cline { 2 - 3 } &
\end{tabular}




\begin{tabular}{|c|c|c|c|c|}
\hline Hết u, không sẹo & 63 & 75 & 16 & 84.2 \\
\hline Còn u & 1 & 1.2 & 0 & 0 \\
\hline Sẹo & 18 & 21.4 & 3 & 15.8 \\
\hline Biến đổi cấu trúc & 1 & 1.2 & 0 & 0 \\
\hline Tụ máu & 1 & 1.2 & 0 & 0 \\
\hline Tổng & 84 & 100 & 19 & 100 \\
\hline
\end{tabular}

Sau hút $2-3$ năm có 19 tổn thương được theo dõi, trong đó $16(84.2 \%)$ tổn thương hết sạch, không để lại sẹo, 3 (15.8\%) tổn thương còn sẹo với thể tích trung bình $0.01 \pm 0.02 \mathrm{~cm}^{3}$
(0.01-0.05 $\left.\mathrm{cm}^{3}\right)$, không thấy tổn thương nào còn sót u, tụ máu hay biến đổi cấu trúc (Bảng 1).

NC của chúng tôi cho thấy mối tương quan tuyến tính thuận giữa thể tích u với sẹo sau hút $(r=0.37, p=0.001)$, giữa số mảnh cắt với sẹo sau hút ( $r=0.42, p=0.0001)$, giữa thời gian hút và sẹo sau hút 1-2 năm $(r=0.39, p=$ $0.0001)$, và giữa máu tụ với sẹo sau hút ( $r=$ $0.68, \mathrm{p}=0.0001$ ). Không có mối tương quan giữa cỡ kim và sẹo sau hút.
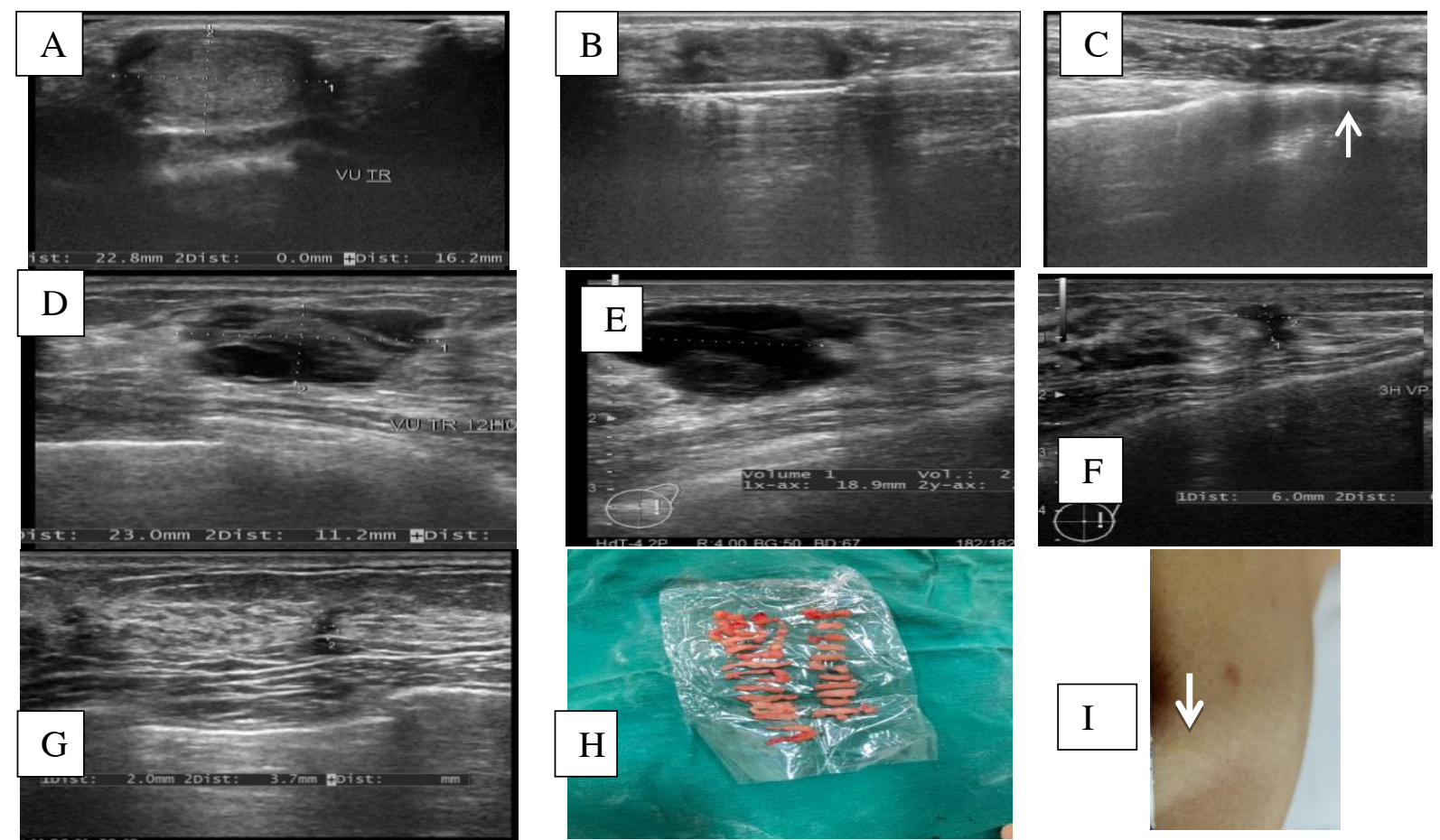

Hình 1. BN nữ 22 tuối, được điều trị hút bỏ u xơ tuyến vú trái bằng phương pháp VABB dưới hướng dẫn siêu âm. Hinh ảnh siêu âm u vú trước khi hút $(A)$, trong khi hút $(B)$ và sau khi hút $(C)$, vị trí khối u sau hút (mũi tên trăng, sau hút 1 ngày $(D)$, sau hút 1 tuần $(E)$, sau hút 1 tháng $(F)$, sau hút 1 năm

$(G)$, các mảnh cắt u sau hút $(H)$ và sẹo sau hút 4 tháng (I) (mũi tên).

Các BN được theo dõi sau điêu trị hút bỏ u vú lành tính đã có kết quả xét nghiệm giải phẫu bệnh trước hút được khẳng định là u lành tính. Chiếm tỷ lệ nhiều nhất là u xơ tuyến vú $(85.8 \%)$. $3(1.6 \%)$ tổn thương có kết quả giải phẫu bệnh là quá sản ống không điển hình, 2 BN đã được đặt dịnh vị kim dây và mổ cắt rộng sau 3 tháng, 1 BN theo dõi sau 6 tháng thãy hết $u$, không để lại sẹo, chưa thăm khám lại sau đó (Bảng 2).

\begin{tabular}{|c|c|c|}
\hline Bệnh tuyến xơ hóa & 6 & 3.2 \\
U tuyến tuyến vú & 1 & 0.5 \\
U nhú nội ống & 1 & 0.5 \\
Quá sản ống thông thường & 4 & 2.1 \\
Quá sản ống không điển hình & 3 & 1.6 \\
\hline Tổng & $\mathbf{1 9 0}$ & $\mathbf{1 0 0}$ \\
\hline
\end{tabular}

\section{BÀN LUẬN}

1. Một số đặc điểm chung của đối tượng Bàng 2. Kêt quả giải phẫu bệnh sau hút

\begin{tabular}{|c|c|c|}
\hline $\begin{array}{c}\text { Kết quả giải phấu bệnh } \\
\text { sau hút }\end{array}$ & $\begin{array}{c}\text { Số tổn } \\
\text { thương }\end{array}$ & $\%$ \\
\hline U xơ tuyến vú & 163 & 85.8 \\
Biến đổi xơ nang & 5 & 2.6 \\
Viêm xơ tuyến vú & 5 & 2.6 \\
U phyllode lành tính & 2 & 1.1 \\
\hline
\end{tabular}

nghiên cứu. Tuổi trung bình của các đối tượng NC (NC) là $32 \pm 9$ (17-65 tuổi), trẻ hơn so với NC của các tác giả Jiang năm 2003², tuổi trung bình là 37.8 .

Về phân bố của u vú, trong NC của chúng tôi, tỉ lệ u vú phải nhiều hơn vú trái, chiếm $55.8 \%$, hay gặp nhất ở vị trí góc $1 / 4$ trên ngoài (43.2\%), 
tương tự các NC trước đó3. Vị trí góc $1 / 4$ trên ngoài là vùng có mật độ mô tuyến dày nhất, có tỉ lệ u vú cao nhất.

2. Đặc điểm hình ảnh siêu âm tuyến vú sau hút u vú 1 tháng. Trong vòng 1 tháng sau hút u vú, theo dõi bằng siêu âm có thể thấy ổ dịch tồn dư giảm âm với hình dáng không đều, ranh giới rõ, có thể có vỏ bọc, không thấy đặc điểm nhu mô tuyến bình thường như "hình ngựa vằn" hoặc "tổ ong", trong một số trường hợp có thể thây nhu mô tuyến gián đoạn đột ngột, điều đó cho thấy ổ dịch tồn dư có thể thấy ở vùng không có nhu mố tuyến, do đó khó xác định giả u tái phát hoặc còn u.

Theo tác giả Yu Ding và cộng sự ${ }^{3}$ nghiên cứu sự thay đổi hình ảnh dưới siểu âm sau hút bỏ u vú lành tính bằng phương pháp VABB đã cho thây biến chứng hay gặp nhất sau hút 1 tháng là máu tụ biểu hiện là vưng giảm âm tại vị trí hút khi theo dỗi sớm sau hút 1 tháng. Sự xuất hiện của máu tụ liên quan đến kích thước, số lượng u, hình dạng của vú và thời gian cố định hiệu quả bằng bằng chun. Trong NC của chúng tôi, tỉ lệ máu tụ chiếm $87.4 \%$, nhỏ hơn so với NC của tác giả Hertl và cộng sự năm $2007^{4}$. Máu tụ xuất hiện có mối tương quan tuyến tính thuận với kích thước (thể tích) u, số mảnh cắt và thời gian hút. Theo kinh nghiệm của chúng tôi, các $B N$ hút nhiều u trong một lần, vú có kích thước lớn và chảy xệ hoặc băng ép không đúng kỹ thuật cũng có thể là yểu tố nguy cơ dẫn đến tăng lượng máu tụ.

Chảy máu, bầm tím da và tụ máu sau thủ thuật có liên quan đến chảy máu. Mặc dù VABB không cần khâu cầm máu, vết rạch kim chỉ 3 $5 \mathrm{~mm}$, và được thực hiện dưới hướng dẫn siêu âm, có thể tìm được đường vào tránh các mạch máu lớn do đó giảm tỷ lệ mất máu trong thủ thuật. Trong quá trình thực hiện, chúng tôi có sử dụng thuốc tê có chứa adrenalin (Lignospan) gây tề quanh u, hút hết máu tồn dư sau thủ thuật, ép cầm máu 10 - 15 phút ngay sau thủ thuật và băng ép bàng băng chun quanh ngực trong 24 giờ. Điều đó cũng giúp giảm tỉ lệ biến chứng sau hút và đã được nhiều tác giả ghi nhận có hiệu quả.

Một số NC đã chỉ ra rằng $73-98 \%$ BN được lấy bổ hoàn toản tổn thương khi kiểm tra sau hút 6 tháng. Nhưng nhiều tháng sau hút vẫn khó phân biệt tổn thương còn lại với máu tụ hoặc sẹo sau hút đặc biệt các tổn thương nhỏ. Do đó, để đánh giá kết quả loại bỏ hoàn toàn tổn thương vú sau hút cân được theo dõi trong một khoảng thời gian dài sau đó.

3. Đặc điểm hình ảnh siêu âm tuyến vú sau hút u vú $1-3$ năm. Tỉ lệ sẹo sau hút trong NC của chúng tôi là $1-2$ năm là $21.4 \%$ giảm xuống $15.8 \%$ sau hút 2 năm, tỉ lệ hết sạch tổn thương từ $75 \%$ sau hút $1-2$ năm tăng lên $84.2 \%$ ở giai đoạn sau hút trên 2 năm, có 1 (1.2\%) tổn thương chưa hết u được phát hiện sau hút u 1 năm, sau hút 2 năm không phát hiện trường hợp nào còn $u$. Kết quả này khá tương đồng với NC của Fine và cộng sự ${ }^{5}$ cho thấy $96-$ $99 \%$ u vú có đường kính $\leq 3 \mathrm{~cm}$ được loại bỏ hoàn toàn bằng phương pháp này. Tuy nhiên theo một số tác giả khác như Thomas Papathemelis năm $2017^{5}$ cho rằng tỉ lệ loại bỏ hoàn toàn các khối u nhỏ hơn $2.5 \mathrm{~cm}^{3}$ là $87.6 \%$ $(p<0.05)$ so với các $u$ có thể tích lớn hơn $2.5 \mathrm{~cm}^{3}$ là $59 \%$ và sau 1 năm tỉ lệ này là $92.3 \%$, có $3.7 \%$ còn sót $u$. Trong $N C$ của chúng tôi, tỉ lệ này thấp hơn có thể do cỡ mẫu chưa đủ lớn, các máy siêu âm có độ phân giải khác nhau.

Theo một số tác giả, do bị giới hạn bởi chiều dài của dao xoay, việc lấy bỏ các khối $3 \mathrm{~cm}$ hoặc lớn hơn kém khả thi. Thực tế NC của chúng tôi có 17/190 (8.9\%) tổn thương có đường kính từ $3 \mathrm{~cm}$ trở lên, trong đó khối lớn nhất có đường kính $5 \mathrm{~cm}$, chỉ có 1 khối không lấy được hết u.

Trường hợp còn sót $u$ của chúng tôi là $B N$ nữ 29 tuổi có khối u xơ với thể tích $20.68 \mathrm{~cm}^{3}$, đường kính lớn nhất $47 \mathrm{~mm}$, nằm sát núm vú, cách da $2 \mathrm{~mm}$, cách cơ ngực $1 \mathrm{~mm}$, trong quá trình thực hiện thủ thuật nhận thấy có nguy cơ rách da và chảy máu, $B N$ đau nhiều do u nằm sát núm vú, do đó chúng tôi đã dừng thủ thuật khu hút được khoảng 90\% thể tích khối u. Sau đó BN được theo dõi định kỳ theo lịch. Sau hút 1 năm, đường kính u còn lại $5 \mathrm{~mm}, \mathrm{BN}$ còn đau nhẹ vết sẹo theo chu kỳ kinh và hài lòng với thủ thuật.

Theo dõi sau thủ thuật $1-2$ năm, chúng tôi thãy thể tích sẹo trung bình là $0.01 \pm 0.03 \mathrm{~cm}^{3}$, sau 2 năm là $0.01 \pm 0.02 \mathrm{~cm}^{3}$, có $1(1.2 \%)$ trường hợp có biến dạng cấu trúc nhỏ sau hút 1 năm, phù hợp với NC của Lee năm $2014^{6}$.

Trong NC của chúng tôi, máu tụ và sẹo sau hút có mối tương quan tuyến tính thuận với nhau và với thể tích, số mảnh cắt, phù hợp với các NC trước đó. Chúng tôi cũng thấy nhóm $\mathrm{BN}$ theo dõi sau 2 năm có thể tích sẹo nhỏ hơn so với nhóm BN theo dõi trước 2 năm $(p=0.001)$, phù hợp với các NC trước đó.

NC của Yazici và cộng sự năm $2005^{7}$ kết luận rằng các tổn thương sau hút cũng ổn định hoẳc thoái triển tương tự các tổn thương sau phẩu thuật; các tổn thương sẹo sau hút có thể có đặc điểm hình ảnh giống tổn thương ác tính tuy nhiên thoái triển hoặc ổn định theo thời gian theo dõi, bác sĩ chẩn đoán hình ảnh cần biết 
được tiền sử và vi trí của u trước thủ thuật để đánh giá một cách chính xác và do đó phân biệt được với các tổn thương ác tính.

Trong NC của chúng tôi, không có tổn thương nào có biến chứng rách da haynhiểm trùng, không có tổn thương nào tái phát. Theo NC phân tích gộp của tác giả Ding $2013^{8}$, tî lệ nhiễm trùng và biến dạng vú ở nhóm phẫu thuật cao hơn VABB.

\section{KẾT LUÂNN}

VABB dưới hướng dẫn siêu âm là một kỹ thuật xâm lấn tối thiểu có tỉ lệ thành công cao trong việc loại bỏ hoàn toàn các u vú lành tính, an toàn, thẩm mỹ, giảm sang chấn về cả thể chất và tinh thần cho $B N$. Hầu hết $B N$ hoàn toàn hài lòng với kết quả của phương pháp. Việc theo dõi dài hạn cho thấy tổn thương sau hút phần lớn không để lại dấu vết hoặc có sẹo và biến dạng cấu trúc nhỏ. Các hình ảnh này thường thoái triển hoặc ổn định qua các lần thăm khám tiếp theo do đó giúp phân biệt với các tổn thương ác tính. Vì vậy, VABB giữ vai trò then chốt trong chỉ định điều trị các u vú lành tính và là xu hướng của các can thiệp xâm lấn tối thiểu trong tương lai.

\section{TÀI LIÊU THAM KHẢO}

1. Lakoma A, Kim ES. Minimally invasive surgical management of benign breast lesions. Gland Surg. 2014;3(2):142-148. doi:10.3978/j.issn.2227-684X. 2014.04.01
2. Jiang $\mathbf{Y}$, Lan $\mathbf{H}, \mathbf{Y e} \mathbf{Q}$, et al. Mammotome $\mathbb{R}$ biopsy system for the resection of breast lesions: Clinical experience in two high-volume teaching hospitals. Exp Ther Med. 2013;6(3):759-764. doi:10.3892/etm.2013.1191

3. Ding Y, Cao L, Chen J, Zaharieva EK, Xu Y, Li L. Serial image changes in ultrasonography after the excision of benign breast lesions by mammotome $\AA$ biopsy system. Saudi J Biol Sci. 2019;26(1): 178-182. doi:10.1016/ j.sjbs.2018.08.016

4. Hertl $K$, Marolt-Music $M$, Kocijančič $I$, Prevodnik-Kloboves V, Žgajnar J. Haematomas After Percutaneus Vacuum-Assisted Breast Biopsy. Ultraschall Med - Eur J Ultrasound. 2008;30(01):33-36. doi:10.1055/s-2007-963724

5. Papathemelis T, Heim S, Lux MP, Erhardt I, Scharl A, Scharl S. Minimally Invasive Breast Fibroadenoma Excision Using an UltrasoundGuided Vacuum-Assisted Biopsy Device. Geburtshilfe Frauenheilkd. 2017;77(2):176-181. doi:10.1055/s-0043-100387

6. Lee EK et al. The usefulness of US-guided vacuum-assisted breast biopsy for probably benign lesions. 2005. 68:90-95.

7. Yazici B, Sever AR, Mills $P$, Fish D, Jones SE, Jones PA. Scar formation after stereotactic vacuum-assisted core biopsy of benign breast lesions. Clin Radiol. 2006;61(7):619-624. doi:10.1016/j.crad.2006.03.008

8. Ding B, Chen $D$, Li $X$, Zhang $H$, Zhao $Y$. Meta analysis of efficacy and safety between Mammotome vacuum-assisted breast biopsy and open excision for benign breast tumor. Gland Surg. 2013;2(2):69-79.

684X.2013.05.06 doi:10.3978/j.issn.2227-

\title{
ĐÁNH GIÁ CHẤT LƯợNG CUỘC SỐNG CỦA NGƯờI BÊNHH RỐI LOẠN NHİP CHẬM SAU CẤY MÁY TẠO NHỊP VĨNH VIỄN
}

\author{
Bạch Thị Hoa*, Phạm Như Hùng*, Nguyễn Thị Phương Thảo*
}

\section{TÓM TẮT}

Đă̆t vấn đề: Đánh giá chất lượng cuộc sông (CLCS) liên quan đến sức khỏe là cần thiết để có được cái nhin tổng quan về CLCS của người bênh, từ đó có chiến lược phù hợp để nâng cao sức khỏe về tinh thần, thể chất cho người bệnh. Mục tiêu của nghiên cứu là mô tả chất lượng cuộc sống của người bệnh rối loạn nhịp chậm sau cây máy tạo nhịp vĩnh viến bằng bộ câu hỏi AQUAREL và SF 12 tại Bệnh viện Tim Hà Nồi. Đối tượng và phương pháp: Nighiên cứu mô tả cắt ngang người bệnh đặt máy tạo nhịp vĩnh viễn tại

\section{*Bệnh viện Tim Hà Nội}

Chịu trách nhiệm chính: Bạch Thị Hoa

Email: bachthihoa@timhanoi.vn

Ngày nhận bài: 5.7.2021

Ngày phản biện khoa học: 31.8.2021

Ngày duyệt bài: 6.9.2021
Bênh viên Tim Hà Nội trong thời gian từ tháng 6/2020 đến 10/2020. Xử lý số liệu theo phần mềm STATA 14. Kết quả: có 105 người bệnh, tuổi trung bình là 65,35 $\pm 13,71$, tỷ lệ nữ giới chiểm $62,86 \%$, theo thang điểm AQUAREL điểm CLCS tốt nhất sau cấy máy là chức năng rối loạn nhịp chậm $(72,52 \pm 16,83 ; 91,19 \pm$ $9,03 ; 96,19 \pm 5,70)$, thấp nhất là khó chiu ở ngực $(60,24 \pm 12,07 ; 86,46 \pm 10,52 ; 95,36 \pm 6,14)$, theo SF - 12 điểm CLCS của sức khỏe tinh thân $(55,62 \pm$ $8,14 ; 56,71 \pm 4,58 ; 56,86 \pm 2,47)$ cao hơn điểm CLCS sức khỏe thể chất $(38,93 \pm 8,07 ; 43,26 \pm 7,89 ; 51,75$ $\pm 5,54)$. Kết luâñ CLCS của người bệnh sau đặt máy tạo nhịp vĩnh viển cải thiện hơn so với trước can thiêp và tăng dân sau $1,3,6$ tháng (theo thang điểm AQUAREL) và tăng tữ mức thấp lên mức khá cao (theo thang điểm SF 12).

Tư khóa: Chất lượng cuộc sống; Máy tạo nhịp vĩnh viễn; Rối loạn nhịp chậm 